\title{
Administration of Quercetin Ameliorates Lipopolysaccharide Induced Neuroinflammation and Oxidative Stress in Adult Zebrafish
}

\author{
Sukhdev Singh \\ ISF College of Pharmacy \\ Kuleshwar Sahu \\ ISF College of Pharmacy \\ Lakshay Kapil \\ ISF College of Pharmacy \\ Charan Singh \\ ISF College of Pharmacy \\ Arti Singh ( $\nabla$ artiniper@gmail.com ) \\ ISF College of Pharmacy https://orcid.org/0000-0001-5168-4930
}

\section{Research Article}

Keywords: Quercetin, Lipopolysaccharide, Neuroinflammation, Oxidative stress

Posted Date: July 29th, 2021

DOI: https://doi.org/10.21203/rs.3.rs-720343/v1

License: (c) (1) This work is licensed under a Creative Commons Attribution 4.0 International License. Read Full License 


\section{Abstract}

Background: Quercetin is a natural flavonoid which is known to have numerous pharmacological activities such as antioxidative, anti-inflammatory and neuroprotective effects against various neurological disorders. Lipopolysaccharide (LPS) is a potent endotoxin, reported to cause various neurological disorders such as Alzheimer's Disease (AD), Parkinson's Disease (PD), Multiple Sclerosis (MS), Amyotrophic Lateral Sclerosis (ALS), Stroke (Brain Attack), Meningitis.

Aim: The present study was designed to investigate the possibility thatquercetin ameliorates LPS induced oxidative stress and neuroinflammation in adult zebrafish.

Materials and methods: Zebrafish (weighing 470-530 mg) were treated with single injection of LPS (1 $\mathrm{mg} / \mathrm{kg}$ ) intraperitoneally (i.p.) followed by post treatment for 7 days with quercetin (50 and $100 \mathrm{mg} / \mathrm{kg}$; i.p.). After sacrificed, brain was harvested and subjected for biochemical, molecular and histological analyses.

Results: Results revealed post treatment with quercetin was able to ameliorate the behavioral abnormalities as in novel diving test- time spent in top zone (TSTZ), and number of entries in top zone was significantly more as compared to time spent in bottom zone (TSBZ). In light-dark chamber test- time spent in light zone (TSLZ), and number of entries in light zone was significantly more as compared to time spent in dark compartment (TSDC). Additionally, results of histopathology (H \& E stain) studies showed less disruption in neuronal cells as compared to LPS treated group. Moreover, results of molecular analysis implies that quercetin treatment significantly decrease TNF- $\alpha$ and IL-1 $\beta$ level as compared to LPS treated animals. Further, results of biochemical analysis reveal that quercetin reduce the level of LPO, nitrite, AChEs and increases anti-oxidant GSH.

Conclusion: Quercetin treatment helps to prevent oxidative damage and neuroinflammation in LPS treated adult zebrafish.

\section{Introduction}

The word "neuroinflammation" as employed here relates to the central nervous system's (CNS) intrinsic cellular reaction to neurodegeneration. The inflammatory response in the CNS is primarily mediated by microglial cells and astrocytes [1]. Microglial cells are the CNS resident macrophages. They represent around $10-12 \%$ of the CNS population [2]. They are important not only for neurogenesis, neuronal plasticity and regeneration but also as a first line of immune defence in any type of brain injury. They have the capability to phagocytose toxic products, releasing cytotoxic factors and act as antigen presenting cells.Microglial cells are in a "resting" condition in the absence of exogenous stimuli, yet their spidery processes are continually examining the immediate surroundings for changes in the brain milieu without interfering with neurons and neuronal activity [1,3]. When activated by a brain injury, they alter morphologically, with the ramified processes becoming amoeboid, and they may migrate toward the lesion site [4]. In our ageing society, brain injuries and neurodegenerative diseases like Alzheimer's 
disease (AD), Parkinson's disease (PD), multiple sclerosis (MS), are growing increasingly widespread, posing a substantial social and economic burden. Adult mammalian CNS have only a limited capacity for regeneration, which includes the replacement of lost neurons (de novo neurogenesis) and the repair of damaged axons (axonal regeneration), traumatic lesions and neurodegeneration drastically reduce quality of life (QoL) and result in severe and frequently fatal impairments [5, 6]. AD is the most wellknown cause of dementia, affecting around 50 million people globally [7], whereas PD affected 6.1 million people worldwide in 2016 [8]. The estimated number of persons living withMS globally grew from 2.1 million in 2008 to 2.3 million in 2013 [9], while the global yearly incidence of Amyotrophic lateral sclerosis (ALS) is around 1.9 per 100,000 [10].

Lipopolysaccharide (LPS) is employed in a variety of neurodegenerative diseases, including AD, PD, ALS, and MS, in experimental in vitro and in vivo models of neuroinflammation and amyloidosis that cause systemic inflammation. LPS is a structural component of Gram-negative bacteria's outer membrane that is localised to the outer layer of the bacterial cell wall and released from the bacterial cell surface in noncapsulated strains. It is made up of three parts: lipid A, a core oligosaccharide, and an 0 side chain [11, 12]. Several studies have shown that LPS causes neuroinflammation by activating microglial cells, which subsequently produce pro-inflammatory cytokines (such as IL-1, TNF-, IL-6, IL-18, and COX-2) [13]. The essential role of LPS in inflammatory responses is first recognised by the TLR-4/CD14 receptor complex expressed in microglia in the CNS, which then stimulates the TLR4/NF-B signalling pathway, which eventually contributes to the secretion of pro-inflammatory cytokines, neuroinflammation, and neurodegeneration [14].

The utility of zebrafish (Danio rerio) as a popular laboratory model for genetics, gene function, and development biology is growing worldwide [15]. Despite the obvious distinctions between fish and mammals, zebrafish and humans are genetically and physiologically similar [16].The zebrafish genome contains orthologs of $71 \%$ of human genes, as well as a high degree of functional conservation in many of the encoded proteins [17]. The chemistry, cellular populations, and basic anatomical structure of the zebrafish and human nervous systems are all evolutionarily conserved [18, 19]. Thus, zebrafish is considered as a suitable model for studying neuroinflammation.

Quercetin is a common natural polyphenolic flavonoid and it is found in a variety of vegetables and fruits [20]. It has been reported to be used as a nutritional supplement and has anti-inflammatory and antioxidant properties, as well as neuroprotective action [21, 22]. Quercetin has been demonstrated to scavenge reactive oxygen radicals and decrease oxidative DNA damage and LPO in many cell-free experimental systems $[23,24]$. In previous studies clearly demonstrated that the quercetin decreased the expression of proinflammatory cytokines (TNF- $a$ and IL-1 $\beta$ ) [25].

Therefore, according to previous studies, we hypothesized that i.p. injection of quercetin could help to protect against the LPS induced neuroinflammation in adult zebrafish. This study further hypothesized that this protective effect could be mediated via decreased in oxidative stress, inflammation and neuronal damage in the brains of adult zebrafish. Thus, the aims of this study were to identify the effect of 
quercetin in LPS induced neuroinflammation and the mechanism underlying its neuroprotective effect, i.e., through amelioration of inflammation, and oxidative stress.

\section{Materials And Methods}

\section{Animals}

Adult zebrafish ( 3 months old, weighing $470-530 \mathrm{mg}$ ) were brought from Aquarts, 26B K Komedanbagan lane, Kolkata, India. Animals were kept in aquarium (94.7L) having temperature $26-27^{\circ} \mathrm{C}$ with constant aeration and $\mathrm{pH}(6-7)$ and were acclimatized by maintaining the experimental room condition. All the animals were kept on a $12 \mathrm{hrs}$ light/dark cycle and were feed twice in a day with commercially available diet (tetrabits). All experiments were conducted in accordance with Institutional Biosafety Committee (IBSC) with approval number ISFCP/IBSC/M1/2020/11.

\section{Chemicals and drug}

LPS and Quercetin were purchased from Sigma-Aldrich (St Louis, Mo, India). ELISA kits of Zebrafish TNF$a$ and IL-1 $\beta$ were purchased from ELK Biotechnology Cat no ELK8512 (Wuhan, China). All other chemicals for biochemical analysis were procured from Himedia and SRL Lmt. All other reagents were of analytical grade and prepared freshly.

\section{Study Design}

Before start the experiment, zebrafish were separated in $1 \mathrm{~L}$ tank with proper aeration and temperature. Total no. of 84 adult zebrafish of both the sexes were used in the study and the animals were divided into different groups as shown in the table (Table 1) with each group having number of animals $12(n=12)$. The seven different groups are (I) Normal group, (II) Vehicle (1\% DMSO), (III) LPS treated group, (IV) Quercetin (50 mg/kg) group, (V) Quercetin (100 mg/kg) group, (VI) LPS + Quercetin (50 mg/kg) group, (VII) LPS + Quercetin (100 mg/kg) group. Detailed experimental protocol is shown in the Fig. 1 . 
Table 1

Animal grouping

\begin{tabular}{|llll|}
\hline S.No. & Groups & Treatment & No. of animals \\
\hline 1. & Control & Normal & 12 \\
\hline 2. & Vehicle & 1\% DMSO; i.p. & 12 \\
\hline 3. & LPS & Lipopolysaccharide $(1 \mathrm{mg} / \mathrm{kg} ;$ i.p. $)$ & 12 \\
\hline 4. & Quercetin & Quercetin $(50 \mathrm{mg} / \mathrm{kg} ;$ i.p. $)$ & 12 \\
\hline 5. & Quercetin & Quercetin $(100 \mathrm{mg} / \mathrm{kg} ;$ i.p. $)$ & 12 \\
\hline 6. & LPS + Quercetin & Post treatment quercetin $(50 \mathrm{mg} / \mathrm{kg} ;$ i.p. $)$ for 7 days & 12 \\
\hline 7. & LPS + Quercetin & Post treatment quercetin $(100 \mathrm{mg} / \mathrm{kg} ;$ i.p. $)$ for 7 days & 12 \\
\hline
\end{tabular}

On the day of the experiment, the adult zebrafish was treated with single i.p. injection of LPS $(1 \mathrm{mg} / \mathrm{kg})$ dissolved in $1 \%$ DMSO at the 0 day. The fishes in normal group were maintained in normal water under identical conditions. In drug treated group, after LPS exposure, the fishes were treated with quercetin, dissolved in $1 \%$ DMSO in concentration of $50 \mathrm{mg} / \mathrm{kg}$ and $100 \mathrm{mg} / \mathrm{kg}$ for 7 days.

\section{Intraperitoneal injection of LPS and quercetin in Zebrafish}

Briefly, each fish was anesthetized by immersion in a tricaine MS-222 solution $100 \mathrm{mg} / \mathrm{L}$ until the animal shows lack of motor coordination and reduced respiration rate. Then after the fish was taken out from the solution and placed on a soft sponge of $20 \mathrm{~mm}$ height which was saturated with water and set into a petri dish [26]. A cut was made on the sponge of about 10-15 mm deep for holding the fish for injection. Then, i.p., injections were conducted using a 31G Ultra-Fine Hamilton Syringe (Himalaya Scientific, Chandigarh, India) according to the protocol previously described. The needle was inserted into the spines posterior to the pectoral fins in the midline of the abdomen. The whole injection procedure should not take more than $10 \mathrm{sec}$ to ensure animal safety and immediately after the injection the animals were placed in a separate tank with unchlorinated water to facilitate the animal recovery from the anaesthesia. After the injection of LPS and Quercetin, the fish was transferred into a separate tank immediately.

\section{Evaluations of behavioral parameters}

\section{Noval diving tank test}

The noval diving tank is used to evaluate anxiety and depression types of behaviour in zebrafish which consisted of $1.5 \mathrm{~L}$ trapezoidal tank with dimension $19 \times 11 \times 22 \mathrm{~cm}$ (height $\mathrm{x}$ length $\mathrm{x}$ breadth). The tank was maximally filled with water and divided into two equal virtual horizontal portions by using a marker on the outside walls [27]. The test was performed for a total of 15 minutes, including a 5-minute 
acclimatization period and a 10-minute for recording. In this test, we have examined the time spent in top zone (TSTZ), time spent in bottom zone (TSBZ), and the number of entries in the top zones during the experiment.

\section{Light-dark chamber test}

The light-dark chamber test is used to analyse spatial memory functions in adult zebrafish[28,29] whichis made up of Plexiglass with dimension $30 \times 16 \times 15 \mathrm{~cm}$ (length $\mathrm{x}$ width $\mathrm{x}$ height) and is separated into two equal parts, one part of which is black while the other half is transparent or white in colour. The apparatus was filled with water up to a height of $10 \mathrm{~cm}$, and fish were placed in it individually. The test was performed for 15 minutes, with the fish being acclimatised for 5 minutes in the dark and 10 min for recording. In this test, we have measured the time spent in the light zone (TSLZ), time spent in dark compartment (TSDC) and the number of entries in light zone. The light and dark chamber test has been identified as a promising behavioural assay for analysing anxiety-like behaviour in adult zebrafish [30].

\section{Evaluations of biochemical parameters}

\section{Tissue preparation}

After the behavioural parameters were performed, the zebrafish were anaesthetized with ice cold water at $4^{\circ} \mathrm{C}$ until the gill movements stopped and they were euthanized. Furthermore, the skull was removed with the help of forceps and micro-dissecting tools. After that, the fish's brains were dissected outand homogenised with $5 \mathrm{ml}$ of $0.1 \mathrm{M}$ phosphate buffer at $\mathrm{pH} 7.2$ in a homogenizing tube [31]. After the homogenate the sample was centrifuged for 10 minutes at $10,000 \mathrm{rpm}$ at $4^{\circ} \mathrm{C}$ and supernatant was used for further analysis.

\section{Estimation of lipid peroxidation}

The lipid peroxidation (LPO) was measured using a procedure previously described by Wills, 1966 [32]. Briefly, $0.5 \mathrm{ml}$ homogenate and add $0.5 \mathrm{ml}$ of Tris $\mathrm{HCL}$ were incubated for 2 hours at $37^{\circ} \mathrm{C} .1 \mathrm{~mL} 10 \%$ tricholroacetic acid (TCA) was added to the incubated solution, followed by 10 minutes of centrifugation at $1000 \mathrm{~g} .1 \mathrm{ml}$ of 0.67 percent thiobarbituric acid (TBA) were added to $1 \mathrm{ml}$ supernatant, and tubes were put in a boiling water bath for 10 minutes before adding $1 \mathrm{ml}$ of double-distilled water, and the level of LPO was measured at $532 \mathrm{~nm}$ absorbance using a Shimadzu spectrophotometer. The final values were calculated using the chromophore's molar extinction coefficient $1.56 \times 10^{5} \mathrm{M}-1 \mathrm{~cm}^{-1}$ and expressed as nmole of MDA per mg protein.

\section{Estimation of Glutathione}


Reduced glutathione activity was estimated by a method described by Ellman et al., 1959 [33]. The homogenate was mix with $1 \mathrm{~mL}$ of $4 \%$ sulfosalicylic acid, then after the sample were centrifugation at $1200 \mathrm{~g}$ for 5 minutes at $4^{\circ} \mathrm{C}$. After centrifugation, $1 \mathrm{~mL}$ of supernatant was added to a test tube with 0.2 $\mathrm{mL}$ of 5,5-dithiobis-(2-nitrobenzoic acid) (DTNB) and $2.7 \mathrm{~mL}$ of phosphate buffer $(0.1 \mathrm{M}, \mathrm{PH} 8)$ and absorbance was measured by Shimadzu spectrophotometer at $412 \mathrm{~nm}$. The enzyme activity was expressed in $\mu \mathrm{mol}$ per $\mathrm{mg}$ protein.

\section{Estimation of Nitrite}

Nitric oxide production was determined in the brain homogenate supernatant based on Greiss reagent [0.1\% Naphthylethylene diamine dihydrogenchloric acid, $1 \%$ Sulphanilamide in $5 \%$ phosphoric acid], and mixed and kept at room temperature for 5 minutes and absorbance was measured by Shimadzu spectrophotometerat $540 \mathrm{~nm}$. The concentration of nitrite was expressed as $\mu \mathrm{mol} / \mathrm{mg}$ protein.

\section{Estimation of protein}

Protein estimation was done by Biuret method (Gornall et al., 1949). $0.1 \mathrm{ml}$ of tissue homogenate supernatant, $2.9 \mathrm{ml} \mathrm{NaCl}$ and $3 \mathrm{ml}$ biuret working reagent were added and kept at room temperature for 10 minutes. The absorbance was measured by Shimadzu spectrophotometer at $536 \mathrm{~nm}$ [34].

\section{Measurement of AChEs activity}

The AChEs enzyme activity was estimated by Ellman method [35]. The assay mixture contained $0.05 \mathrm{ml}$ of supernatant, $3 \mathrm{ml}$ of $0.01 \mathrm{M}$ Sodium phosphate buffer $(\mathrm{pH} 8), 0.10 \mathrm{ml}$ of ACh iodide and $0.10 \mathrm{ml}$ of $5,5-$ dithio-bis (2-nitrobenzoic acid) (DTNB) (Ellman reagent). The change in absorbance was measured immediately at $412 \mathrm{~nm}$ using Shimadzu spectrophotometer. Results were expressed as micromoles of acetyl thiocholine iodide hydrolyzed/min/mg of protein.

\section{Estimation of pro-inflammatory cytokines (TNF- $\alpha$ and IL-1 $\beta$ ) levels}

The pool of 3 brain tissues was homogenized and prepared in PBS (mM) $(50 \mathrm{NaCl}, 18 \mathrm{Na} 2 \mathrm{HPO} 4,83$ $\mathrm{NaH} 2 \mathrm{PO} 4 . \mathrm{H} 2 \mathrm{O}, \mathrm{pH}$ 7.4), containing $1 \mathrm{mM}$ EGTA and $1 \mathrm{mM} \mathrm{PMSF}$, followed by centrifugation at $1000 \times g$ for $5 \mathrm{~min}$ at $4^{\circ} \mathrm{C}$. This assay was carried out in $100 \mu \mathrm{L}$ of supernatant, by using TNF-a and IL-1 $\beta$ ELISA kits according to the manufacturer's protocol (ELK Biotechnology Cat no ELK8512 (Wuhan, China)[36].

\section{Histopathological analysis}


Animals were sacrificed by decapitation immediately after the last behavioral test. The brain were removed and transferred to formalin $(10 \% \mathrm{v} / \mathrm{v})$. The brain tissues were embedded in paraffin blocks and sectioned into $3 \mathrm{~mm}$ thickness with the help of a microtome. The brain sections $(5-10 \mu \mathrm{m})$ thick were dewaxed and stained with $\mathrm{H} \& \mathrm{E}$ [37]. The stained sections were examined at 40X under a fluorescence microscope (Model: 102 M, Motic microscope, China).

\section{Statistical Analysis}

GraphPad Prism 5.0 software for Windows (GraphPad Software, San Diego, CA, USA), was used to analyse all data, which was presented as mean \pm SEM.Values were expressed as the mean \pm SD. The behavioural, biochemical and neuroinflammatory assessment data was evaluated using one-way analysis of variance. Post hoc comparisons between groups were made by using Tukey's test. A value of $p<0.05$ was considered statistically significant.

\section{Results}

\section{Effect of quercetin treatment on novel diving tank in LPS treated zebrafish}

The normal, vehicle and quercetin $(50,100 \mathrm{mg} / \mathrm{kg})$ per se group didn't show any significant effect in novel diving test.Figure 2 A shows that single injection of LPS $(1 \mathrm{mg} / \mathrm{kg})$ significantly affected the zebrafish behaviour, as TSTZ was significantly $(p<0.001)$ less as compared to normal group. However, treatment with quercetin $(50 \mathrm{mg} / \mathrm{kg}$ and $100 \mathrm{mg} / \mathrm{kg}$ ) significantly reverse the effect produced by the LPS by spending more time in top zone as compared to LPS treated animals $(p<0.001)$. Moreover, the effect of treatment with quercetin $(100 \mathrm{mg} / \mathrm{kg})$ was found to be significantly greater in ameliorating the TSTZ when compared to the effect of quercetin $(50 \mathrm{mg} / \mathrm{kg})(\mathrm{p}<0.01)$.

Figure 2 B shows that single injection of LPS $(1 \mathrm{mg} / \mathrm{kg})$ significantly affected the zebrafish behaviour, as TSBZ was significantly $(p<0.001)$ more as compared to normal group. However, treatment with quercetin (50 mg/kg and $100 \mathrm{mg} / \mathrm{kg}$ ) significantly reverse the effect produced by the LPS by spending less time in bottom zone as compared with LPS treated group $(p<0.001)$. Moreover, the effect of treatment with quercetin $(100 \mathrm{mg} / \mathrm{kg})$ was found to be significantly attenuated the TSBZ when compared to the effect of quercetin $(50 \mathrm{mg} / \mathrm{kg})(\mathrm{p}<0.01)$.

Figure $2 \mathrm{C}$ shows that single injection of LPS $(1 \mathrm{mg} / \mathrm{kg})$ significantly affected the zebrafish behaviour, as number of entries in the top zone was significantly $(p<0.001)$ less as compared to normal group. However, treatment with quercetin ( $50 \mathrm{mg} / \mathrm{kg}$ and $100 \mathrm{mg} / \mathrm{kg}$ ) significantly reverse the effect produced by the LPS by increasing number of entries in top zone as compared with LPS treated animals $(p<0.001)$. Moreover, the effect of treatment with quercetin $(100 \mathrm{mg} / \mathrm{kg})$ was found to be significantly greater in ameliorating this effect when compared to quercetin $(50 \mathrm{mg} / \mathrm{kg})(\mathrm{p}<0.01)$. 


\section{Effect of quercetin treatment on light-dark chamber test in LPS treated zebrafish}

The normal, vehicle and quercetin $(50,100 \mathrm{mg} / \mathrm{kg})$ per se group didn't show any significant effect in light and dark chamber test. Figure 3 A shows that single i.p. administration of LPS ( $1 \mathrm{mg} / \mathrm{kg})$ significantly affected the zebrafish behaviour, as TSLZ was significantly $(p<0.001)$ less as compared to normal group. However, treatment with quercetin (50 mg/kg and $100 \mathrm{mg} / \mathrm{kg}$ ) significantly reverse the effect produced by the LPS by spending more time in light zone as compared to LPS treated animals $(p<0.001)$. Moreover, the effect of treatment with quercetin $(100 \mathrm{mg} / \mathrm{kg})$ was found to be significantly greater in ameliorating the TSLZ when compared to the effect of quercetin $(50 \mathrm{mg} / \mathrm{kg})(p<0.01)$.

Figure 3 B shows that single i.p. injection of LPS $(1 \mathrm{mg} / \mathrm{kg})$ significantly affected the zebrafish behaviour, as TSDC was significantly $(p<0.001)$ less as compared to normal group. However, treatment with quercetin $(50 \mathrm{mg} / \mathrm{kg}$ and $100 \mathrm{mg} / \mathrm{kg}$ ) significantly reverse the effect produced by LPS by spending less time indark compartment as compared to LPS treated animals $(\mathrm{p}<0.001)$. Moreover, the effect of treatment with quercetin $(100 \mathrm{mg} / \mathrm{kg})$ was found to be significantly reduce in ameliorating the TSDC when compared to the effect of quercetin $(50 \mathrm{mg} / \mathrm{kg})(\mathrm{p}<0.01)$.

Figure $3 \mathrm{C}$ shows that single injection of LPS $(1 \mathrm{mg} / \mathrm{kg})$ significantly affected the zebrafish behaviour, as number of entries in light zone was significantly $(p<0.001)$ less as compared to normal group. However, treatment with quercetin $(50 \mathrm{mg} / \mathrm{kg}$ and $100 \mathrm{mg} / \mathrm{kg}$ ) significantly reverse the effect produced by the LPS by increasing number of entries in light zone as compared with LPS treated animals $(p<0.001)$. Moreover, the effect of treatment with quercetin $(100 \mathrm{mg} / \mathrm{kg})$ was found to be significantly greater in ameliorating this effect when compared to quercetin $(50 \mathrm{mg} / \mathrm{kg})(p<0.01)$.

\section{Assessment of oxidative stress markers}

\subsection{Effect of quercetin treatment on LPO level in LPS treated zebrafish}

Figure 4 A shows, the level of LPO in normal, vehicle and quercetin $(50,100 \mathrm{mg} / \mathrm{kg})$ per se group didn't show any significant effect. Single injection of LPS $(1 \mathrm{mg} / \mathrm{kg})$ treated adult zebrafish showed significantly increased oxidative stress due to increase in LPO level as compared with normal group $(p<0.001)$. However, treatment with quercetin $(50,100 \mathrm{mg} / \mathrm{kg})$ for 7 days significantly reduced LPO level as compared to LPS treated group $(p<0.001)$. Moreover, quercetin $(100 \mathrm{mg} / \mathrm{kg})$ showed significantly reduced the level of LPO as compared with quercetin $(50 \mathrm{mg} / \mathrm{kg})$ treated group $(p<0.01)$. 


\subsection{Effect of quercetin treatment on nitrite level in LPS treated zebrafish}

Figure 4 B shows, in normal, vehicle and quercetin $(50,100 \mathrm{mg} / \mathrm{kg})$ per se group didn't show any significant effect on nitrite level. Single i.p. administration of LPS $(1 \mathrm{mg} / \mathrm{kg})$ treated brain of adult zebrafish showed significantly raised in nitrite level as compared with normal group $(p<0.001)$. Moreover, treatment with quercetin $(50,100 \mathrm{mg} / \mathrm{kg})$ for 7 days significantly reduced the level of nitrite as compared with LPS treated group ( $\mathrm{p}<0.001)$. Furthermore, quercetin $(100 \mathrm{mg} / \mathrm{kg})$ showed significantly reduced nitrite level as compared with quercetin $(50 \mathrm{mg} / \mathrm{kg})$ treated group $(\mathrm{p}<0.01)$.

\subsection{Effect of quercetin treatment on AChEs level in LPS treated zebrafish}

Figure $4 \mathrm{C}$ shows, the level of AChEs in normal, vehicle and quercetin $(50,100 \mathrm{mg} / \mathrm{kg})$ per se group didn't show any significant effect. Single injection of LPS $(1 \mathrm{mg} / \mathrm{kg})$ showed increased the level of AChEs as compared with normal group $(p<0.001)$. Increased AChEsis associated with memory impairment. After treatment with quercetin ( 50 and $100 \mathrm{mg} / \mathrm{kg}$ ) for 7 days significantly reduced memory impairment as decrease in AChEs level as compared to LPS treated group $(p<0.001)$. Moreover, quercetin $(100 \mathrm{mg} / \mathrm{kg})$ showed significantly decreased AChEs level as compared with quercetin $(50 \mathrm{mg} / \mathrm{kg})$ treated group $(p<0.01)$.

\subsection{Effect of quercetin treatment on GSH level in LPS treated zebrafish}

Figure4 Dshows, the GSH level in normal, vehicle and quercetin $(50,100 \mathrm{mg} / \mathrm{kg})$ per se group didn't show any significant effect. The GSH level in the brain of adult zebrafish treated with a single intraperitoneal injection of LPS $(1 \mathrm{mg} / \mathrm{kg}$ ) was significantly lower as compared to normal group $(\mathrm{p}<0.001)$. Furthermore, compared to the LPS-treated group, treatment with quercetin $(50,100 \mathrm{mg} / \mathrm{kg})$ for 7 days significantly raised the level of GSH $(p<0.001)$. Furthermore, quercetin $(100 \mathrm{mg} / \mathrm{kg})$ showed significantlyincreased GSH level as compared with quercetin $(50 \mathrm{mg} / \mathrm{kg})$ treated group $(\mathrm{p}<0.01)$.

\section{Effect of quercetin treatment on TNF- $a$, IL-1 $\beta$ level in LPS treated zebrafish.}

Figure 5 shown, in normal, vehicle and quercetin $(50,100 \mathrm{mg} / \mathrm{kg})$ per se group didn't show any significant effect on TNF-a andIL-1 $\beta$. Figure 5 A shown, Single injection of LPS $(1 \mathrm{mg} / \mathrm{kg})$ in zebrafish brain showed a significant increased level of TNF-ain adult zebrafish brain as compared with the normal group $(\mathrm{p}<$ 0.001). However, treatment with quercetin (50 and $100 \mathrm{mg} / \mathrm{kg}$ ) has significantly reduced the level of TNF- 
aas compared with the LPS treated group ( $\mathrm{p}$ 0.001). Moreover, quercetin $(100 \mathrm{mg} / \mathrm{kg})$ showed significantlydecreased level of TNF-a as compared withquercetin $(50 \mathrm{mg} / \mathrm{kg})$ treated group $(p<0.01)$.

Figure 5 B shown, Single injection of LPS $(1 \mathrm{mg} / \mathrm{kg})$ in zebrafish brain showed a significant increased level of IL-1 $\beta$ in adult zebrafish brain as compared with the normal group $(p<0.001)$. However, treatment with quercetin (50 and $100 \mathrm{mg} / \mathrm{kg}$ ) has significantly reduced the level of IL-1 $\beta$ as compared with the LPS treated group ( $p<0.001)$. Moreover, quercetin $(100 \mathrm{mg} / \mathrm{kg})$ showed significantly decreased level of IL-1 $\beta$ as compared withquercetin $(50 \mathrm{mg} / \mathrm{kg})$ treated group $(\mathrm{p}<0.01)$.

\section{Histopathological analysis- Effect of quercetin treatment on histopathological damagesin LPS treated zebrafish.}

Figure 6 shows, histopathological evaluation of brain tissue was carried on under light microscopy. In the histopathological study, the brains of normal, vehicle and per se treated groups showed undamaged neuronal cells. However, treatment with LPS $(1 \mathrm{mg} / \mathrm{kg})$ causes disarrangement of various cell layers as well as the pyramidal neuronal cell loss was found which was significant as compared to the normal group. However, treatment with quercetin (50 and $100 \mathrm{mg} / \mathrm{kg}$ ) significantly attenuated the loss of neuronal cell density as compared to LPS treated animals.

\section{Discussion}

In the present study, we have evaluated the potential preventive role of quercetin to attenuate LPS induced neuroinflammation in adult zebrafish. In accordance to previous studies showed that LPS is an endotoxin, found in outer membrane of gram-negative bacteria. It is potent activator of immune system. Immunocytes detect LPS through the TLR4, which it binds to with high affinity and activated microglia. Microglia, which are resident innate immune cells in the CNS, play an important role in the inflammatory process [38]. The activation of microglia generates various pro-inflammatory cytokines (TNF-a, IL-1 $\beta$, IL-6, iNOS, COX-2), causing damage to surrounding neurons and eventually inducing neurodegeneration [39, 40], in macrophages LPS activated NFkB and mitogen-activated protein kinases (MAPKs) [41]. Sickness behaviour, impaired memory, and depression-like behaviour are all symptoms of increased neuroinflammation. These findings showed that LPS enhanced oxidative stress and neuroinflammation, which can lead to neurological diseases such as anxiety, sadness, and memory loss.

According to the literature review, the Noval Diving test and the Light-Dark test are used to evaluate anxiety, depression, and memory functions. When normal zebrafish are exposed to a new environment, they swim to the bottom and progressively explore the top compartment of the novel tank apparatus, increasing the time spent and the number of entries in the top zone. Normal zebrafish prefer the light chamber as compared to the dark compartment in a light-dark test. Anxiolytic, locomotor, and memory functions are all assessed using the light-dark test[42, 43]. In our study, we have developed the model of LPS induced neuroinflammation in adult zebrafish and our findings revealed that a single injection of 
LPS ( $1 \mathrm{mg} / \mathrm{kg}$; i.p.) on day 0 of the procedure caused significant behavioural and biochemical alterations. In a novel diving test, the LPS-treated group significantly increased TSBZ while dramatically reducing TSTZ and the number of entries into the top compartment as compared to the normal group. The enhanced TSBZ was the measure of anxiety. In the light dark test, the LPS treated group showed significantly less TSLZ as well as reduced number of entries in the light zone and greater the preference in dark compartment as compared with the normal group. The increased TSDC and number of entries was the measure of depression and anxiety like state.

According to the previous studies, quercetin is a natural flavonoid, found in various vegetables, fruits, leaves and grains [44]. Quercetin is a natural antioxidant with anti-inflammatory properties, as well as the ability to prevent pro-inflammatory cytokine production and microglia activation in vivo and in vitro [45]. Various investigations have shown that it can function as a scavenger of reactive oxygen species, protecting tissues from free radicals [46]. Quercetin is significant to aquaculture since its beneficial qualities have been explored as a possible addition in fish diet [47]. In our work, different doses of quercetin (50 and $100 \mathrm{mg} / \mathrm{kg}$; i.p.) were used to check the antioxidant potential. Our results showed, both doses reversed the preferences as compared to the LPS treated groups in novel diving test and light-dark chamber test. In novel diving test, post-treatment group of quercetin (50 and $100 \mathrm{mg} / \mathrm{kg}$ ) explore both zone showing more preference in top zone thus significantly increasing the TSTZ and the no. of entries to the top. Reduced behaviour sickness is shown by the treatment group's return to normal exploratory behaviour. The light-dark compartment test revealed that the quercetin (50 and $100 \mathrm{mg} / \mathrm{kg}$ ) posttreatment group favoured the light compartment, which resulted in significantly more TSLZ and number of entries in the light compartment. The TSDC is an indication of depression and anxiety like state which is significantly decreased in the treatment groups.

As previously mentioned, the oxidative stress parameter can be used to indicate anxiety and depressionlike behaviour [48]. The level of LPO assessed in biochemical estimates is used to represent increased oxidative stress and enhanced the production of nitrite level [49]. In addition, GSH is an antioxidant, that reduced its level in neuroinflammation [50]. Keeping the above cascade in mind we also found significantly increased the level of LPO, nitrite and decreased level of GSH in LPS treated zebrafish brain as compared with normal group. On the other hand, quercetin is an antioxidant potentially [51,52]. We found that post-treatment with quercetin (50 and $100 \mathrm{mg} / \mathrm{kg}$ ) significantly reduced oxidative stress, LPO, nitrite level and increased in GSH level.

Acetylcholinesterase (AChEs) levels were measured to see whether LPS caused memory impairment. The activity of acetylcholinesterase is altered by LPS, which suppresses the activity of acetylcholine, which is responsible for memory and learning $[53,54]$. our investigation, the LPS-treated group had higher levels of AChEs as seen against normal group, indicating memory impairment. Whereas quercetin (50 and 100 $\mathrm{mg} / \mathrm{kg}$ ) treated group significantly decreased the level of AChEs in zebrafish brain.

Through previous studies, LPS increased the level of inflammatory cytokines such as TNF- $a$ and IL-1 $\beta$ in the brain via activation of microglia and astrocytes $[55,56]$. Our study also showed similar results 
according to previous studies, in the LPS treated group increased level of TNF- $\alpha$ and IL-1 $\beta$ as compared with the normal group. However, treatment with quercetin (50 and $100 \mathrm{mg} / \mathrm{kg}$ ) decreased the level of TNF- $\alpha$ and IL-1 $\beta$ as compared with LPS treated group.

Histopathological evidence revealed damaged morphology in the LPS administration group which was confirmed by the pyramidal neuronal cell loss and also disarrangement of various cell layers. Moreover quercetin (50 and $100 \mathrm{mg} / \mathrm{kg}$ ) attenuate the above given morphological damage.

Post treatment with quercetin (50 and $100 \mathrm{mg} / \mathrm{kg}$ ) significantly reduced in the anxiety and depression like behaviour and improved memory functions by changing the behavioural and biochemical parameters performed and attenuated proinflammatory cytokines. Quercetin $(100 \mathrm{mg} / \mathrm{kg})$ showed marked reduction by altering above the given parameters as compared with quercetin $(50 \mathrm{mg} / \mathrm{kg})$. Based on the favourable results, it was determined that quercetin had a protective effect on LPS-induced behaviour illness by decreasing lipid peroxidation and its products, as well as delaying the neuroinflammation caused by LPS (figure 7).

\section{Conclusion}

In this study, we investigated the neuroprotective effect of quercetin against LPS induced neuroinflammation in adult zebrafish. It was concluded that the beneficial effects of quercetin on brain like anxiety, depression, locomotor activity and memory as illustrated by novel diving and light-dark chamber test may be due to its neuroprotective potential which can correlated with its antioxidant and anti-inflammatory activities. Various mechanisms may be working in the CNS and induce neurological changes in neuroinflammation. However, further studies on basic cellular and molecular grounds are required to understand the deficits induced by LPS.

\section{Abbreviations}

LPS :Lipopolysaccharide
AD :Alzheimer Disease
PD :Parkinson Disease

MS :Multiple Sclerosis

ALS :Amyotrophic Lateral Sclerosis

TSTZ :Time spent in top zone

TSBZ :Time spent in bottom zone

TSLZ :Time spent in light zone 
TSDC :Time spent in dark compartment

TNF- $\mathbf{a}$ :Tumour necrosis factor

IL-1 $\beta$ : Interleukin 1 beta

LPO : Lipid peroxidation

AChEs : Acetylcholinesterase

GSH :Glutathione

CNS : Central nervous system

QoL :Quality of life

BBB :Blood- brain barrier

DMSO :Dimethlsulfoxide

TCA :Tricholroacetic acid

TBA :Thiobarbituric acid

\section{Declarations}

\section{Author contribution}

Sukhdev Singh did the research, Kuleshwar Sahu and Lakshay Kapil helped in data collection, Charan Singh helped in editing the manuscript, Arti Singh design the layout and critically revise the manuscript. The authors declare that all data were generated in-house and that no paper mill was used.

\section{Acknowledgments}

Authors are thankful to Shri. Parveen Garg, Chairman, and Dr. G.D. Gupta Director, ISFCP, for providing research facility. Biorender.com for the preparation of figures.

\section{Conflict of interest}

All authors confirm and declare no competing financial interests.

\section{References}


1. Morales I, Guzmán-Martínez L, Cerda-Troncoso C, Farías GA, Maccioni RB. Neuroinflammation in the pathogenesis of Alzheimer's disease. A rational framework for the search of novel therapeutic approaches. Frontiers in cellular neuroscience. 2014 Apr 22;8:112

2. Heneka MT, O'Banion MK. Inflammatory processes in Alzheimer's disease. Journal of neuroimmunology. 2007 Mar 1;184(1-2):69-91

3. Hanisch UK, Kettenmann H (2007 Nov) Microglia: active sensor and versatile effector cells in the normal and pathologic brain. Nature neuroscience 10(11):1387-1394

4. Kreutzberg GW. Microglia: a sensor for pathological events in the CNS. Trends in neurosciences. 1996 Aug 1;19(8):312-8

5. Pernet $\mathrm{V}$, Schwab ME. Lost in the jungle: new hurdles for optic nerve axon regeneration. Trends in neurosciences. 2014 Jul 1;37(7):381-7

6. Tuszynski MH, Steward 0 . Concepts and methods for the study of axonal regeneration in the CNS. Neuron. 2012 Jun 7;74(5):777-91

7. Rusek M, Pluta R, Ułamek-Kozioł M, Czuczwar SJ (2019 Jan) Ketogenic diet in Alzheimer's disease. Int J Mol Sci 20(16):3892

8. Dorsey ER, Elbaz A, Nichols E, Abd-Allah F, Abdelalim A, Adsuar JC, Ansha MG, Brayne C, Choi JY, Collado-Mateo D, Dahodwala N (2018) Global, regional, and national burden of Parkinson's disease, 1990-2016: a systematic analysis for the Global Burden of Disease Study 2016. The Lancet Neurology. Nov 1;17(11):939 - 53

9. Browne P, Chandraratna D, Angood C, Tremlett H, Baker C, Taylor BV, Thompson AJ (2014 Sep) Atlas of multiple sclerosis 2013: a growing global problem with widespread inequity. Neurology 9(11):1022-1024 83(

10. Chiò A, Logroscino G, Traynor BJ, Collins J, Simeone JC, Goldstein LA, White LA (2013) Global epidemiology of amyotrophic lateral sclerosis: a systematic review of the published literature. Neuroepidemiology 41(2):118-130

11. Zakaria R, Wan Yaacob WM, Othman Z, Long I, Ahmad AH, Al-Rahbi B. Lipopolysaccharide-induced memory impairment in rats: a model of Alzheimer's disease. Physiological research. 2017 Aug 1;66

12. Lu YC, Yeh WC, Ohashi PS. LPS/TLR4 signal transduction pathway. Cytokine. 2008 May 1;42(2):145-51

13. de Oliveira AC, Yousif NM, Bhatia HS, Hermanek J, Huell M, Fiebich BL (2016 Dec) Poly (I: C) increases the expression of mPGES-1 and COX-2 in rat primary microglia. Journal of neuroinflammation 13(1):1-1

14. Yao L, Kan EM, Kaur C, Dheen ST, Hao A, Lu J, Ling EA (2013 Nov) Notch-1 signaling regulates microglia activation via NF-KB pathway after hypoxic exposure in vivo and in vitro. PloS one 6(11):e78439 8(

15. Bradford YM, Toro S, Ramachandran S, Ruzicka L, Howe DG, Eagle A, Kalita P, Martin R, Taylor Moxon SA, Schaper K, Westerfield M (2017) Zebrafish models of human disease: gaining insight into human disease at ZFIN. ILAR journal. Jul 1;58(1):4-16 
16. Williams $\mathrm{CH}$, Hong CC (2011 Apr) Multi-step usage of in vivo models during rational drug design and discovery. Int J Mol Sci 12(4):2262-2274

17. Howe K, Clark MD, Torroja CF, Torrance J, Berthelot C, Muffato M, Collins JE, Humphray S, McLaren K, Matthews L, McLaren S (2013 Apr) The zebrafish reference genome sequence and its relationship to the human genome. Nature 496(7446):498-503

18. Kalueff AV, Stewart AM, Gerlai R. Zebrafish as an emerging model for studying complex brain disorders. Trends in pharmacological sciences. 2014 Feb 1;35(2):63-75

19. Lieschke GJ, Currie PD (2007 May) Animal models of human disease: zebrafish swim into view. Nat Rev Genet 8(5):353-367

20. Singh S, Jamwal S, Kumar P (2017 Jul) Neuroprotective potential of Quercetin in combination with piperine against 1-methyl-4-phenyl-1, 2, 3, 6-tetrahydropyridine-induced neurotoxicity. Neural regeneration research 12(7):1137

21. Zhang ZJ, Cheang LC, Wang MW, Lee SM (2011) Quercetin exerts a neuroprotective effect through inhibition of the iNOS/NO system and pro-inflammation gene expression in PC12 cells and in zebrafish. International journal of molecular medicine. Feb 1;27(2):195-203

22. Richetti SK, Blank M, Capiotti KM, Piato AL, Bogo MR, Vianna MR, Bonan CD (2011 Feb) Quercetin and rutin prevent scopolamine-induced memory impairment in zebrafish. Behav Brain Res 217(1) (2):10-15

23. Cai Q, Rahn RO, Zhang R (1997 Oct) Dietary flavonoids, quercetin, luteolin and genistein, reduce oxidative DNA damage and lipid peroxidation and quench free radicals. Cancer letters 28(1):99-107 119(

24. Husain SR, Cillard J, Cillard P. Hydroxyl radical scavenging activity of flavonoids. Phytochemistry. 1987 Jan 1;26(9):2489-91

25. Bournival J, Plouffe M, Renaud J, Provencher C, Martinoli MG (2012) Quercetin and sesamin protect dopaminergic cells from MPP+-induced neuroinflammation in a microglial (N9)-neuronal (PC12) coculture system. Oxidative medicine and cellular longevity. Oct;2012

26. Singh S, Jamwal S, Kumar P (2017 Jul) Neuroprotective potential of Quercetin in combination with piperine against 1-methyl-4-phenyl-1, 2, 3, 6-tetrahydropyridine-induced neurotoxicity. Neural regeneration research 12(7):1137

27. Stewart A, Cachat JM, Suciu C, Hart PC, Gaikwad S, Utterback E, DiLeo J, Kalueff AV. Intraperitoneal injection as a method of psychotropic drug delivery in adult zebrafish. InZebrafish neurobehavioral protocols 2011 (pp. 169-179). Humana Press

28. Egan RJ, Bergner CL, Hart PC, Cachat JM, Canavello PR, Elegante MF, Elkhayat SI, Bartels BK, Tien AK, Tien DH, Mohnot S (2009) Understanding behavioral and physiological phenotypes of stress and anxiety in zebrafish. Behavioural brain research. Dec 14;205(1):38-44

29. Singh A, Subhashini N, Sharma S, Mallick BN (2013 Aug) Involvement of the a1-adrenoceptor in sleep-waking and sleep loss-induced anxiety behavior in zebrafish. Neuroscience 15:245:136-147 
30. Dubey S, Ganeshpurkar A, Bansal D, Dubey N (2015 Jan) Protective effect of rutin on impairment of cognitive functions of due to antiepileptic drugs on zebrafish model. Indian J Pharmacol 47(1):86

31. Stewart A, Maximino C, De Brito TM, Herculano AM, Gouveia A, Morato S, Cachat JM, Gaikwad S, Elegante MF, Hart PC, Kalueff AV. Neurophenotyping of adult zebrafish using the light/dark box paradigm. InZebrafish neurobehavioral protocols 2011 (pp. 157-167). Humana Press

32. Gupta T, Mullins MC. Dissection of organs from the adult zebrafish. Journal of visualized experiments: JoVE. 2010(37)

33. Wills E (1966 Jun) Mechanisms of lipid peroxide formation in animal tissues. Biochemical journal 99(3):667-676

34. Ellman GL (1959) Tissue sulfhydryl groups. Archives of biochemistry and biophysics. May 1;82(1):70 $-7$

35. Itzhaki RF, Gill DM. A micro-biuret method for estimating proteins. Analytical biochemistry. 1964 Dec 1;9(4):401 - 10

36. Ellman GL, Courtney KD, Andres V Jr, Featherstone RM (1961 Jul) A new and rapid colorimetric determination of acetylcholinesterase activity. Biochem Pharmacol 7(2)(1):88-95

37. Peterson GL. A simplification of the protein assay method of Lowry et al (1977) which is more generally applicable. Analytical biochemistry. Dec 1;83(2):346 - 56

38. Singh A, Kumar A. Microglial inhibitory mechanism of coenzyme Q10 against $A \beta(1-42)$ induced cognitive dysfunctions: possible behavioral, biochemical, cellular, and histopathological alterations. Frontiers in pharmacology. 2015 Nov 9;6:268

39. Fu SP, Wang JF, Xue WJ, Liu HM, Liu BR, Zeng YL, Li SN, Huang BX, Lv QK, Wang W, Liu JX (2015 Dec) Anti-inflammatory effects of BHBA in both in vivo and in vitro Parkinson's disease models are mediated by GPR109A-dependent mechanisms. J Neuroinflamm 12(1):1-4

40. Raetz CR, Whitfield C (2002 Jul) Lipopolysaccharide endotoxins. Annual review of biochemistry 71(1):635-700

41. Sulakhiya K, Kumar P, Gurjar SS, Barua CC, Hazarika NK (2015 May) Beneficial effect of honokiol on lipopolysaccharide induced anxiety-like behavior and liver damage in mice. Pharmacology Biochemistry Behavior 1:132:79-87

42. Hwang D, Jang BC, Yu G, Boudreau M (1997) Expression of mitogen-inducible cyclooxygenase induced by lipopolysaccharide: mediation through both mitogen-activated protein kinase and NF-kB signaling pathways in macrophages. Biochemical pharmacology. Jul 1;54(1):87-96

43. Mezzomo NJ, Silveira A, Giuliani GS, Quadros VA, Rosemberg DB (2016 Feb) The role of taurine on anxiety-like behaviors in zebrafish: a comparative study using the novel tank and the light-dark tasks. Neurosci Lett 2:613:19-24

44. Peng X, Lin J, Zhu Y, Liu X, Zhang Y, Ji Y, Yang X, Zhang Y, Guo N, Li Q. Anxiety-related behavioral responses of pentylenetetrazole-treated zebrafish larvae to light-dark transitions. Pharmacology Biochemistry and Behavior. 2016 Jun 1;145:55-65 
45. Wach A, Pyrzyńska K, Biesaga M (2007) Quercetin content in some food and herbal samples. Food chemistry. Jan 1;100(2):699-704

46. Yang Y, Liu X, Wu T, Zhang W, Shu J, He Y, Tang SJ (2018) Quercetin attenuates AZT-induced neuroinflammation in the CNS. Scientific reports. Apr 18;8(1):1-8

47. Boots AW, Li H, Schins RP, Duffin R, Heemskerk JW, Bast A, Haenen GR (2007) The quercetin paradox. Toxicology and applied pharmacology. Jul 1;222(1):89-96

48. Pês TS, Saccol EM, Ourique GM, Londero ÉP, Gressler LT, Golombieski JI, Glanzner WG, Llesuy SF, Gonçalves PB, Neto JR, Baldisserotto B (2016) Quercetin in the diet of silver catfish: effects on antioxidant status, blood parameters and pituitary hormone expression. Aquaculture. May 1;458:1006

49. Patki G, Solanki N, Atrooz F, Allam F, Salim S. Depression, anxiety-like behavior and memory impairment are associated with increased oxidative stress and inflammation in a rat model of social stress. Brain research. 2013 Nov 20;1539:73-86

50. Page LE (1999 Nov) Benznidazole, a drug employed in the treatment of Chagas' disease, downregulates the synthesis of nitrite and cytokines by murine stimulated macrophages. Clinical Experimental Immunology 118(2):271-277

51. Tyagi E, Agrawal R, Nath C, Shukla R. Influence of LPS-induced neuroinflammation on acetylcholinesterase activity in rat brain. Journal of neuroimmunology. 2008 Dec 15;205(1-2):51-6

52. Unsal C, Kanter M, Aktas C, Erboga M (2015 Dec) Role of quercetin in cadmium-induced oxidative stress, neuronal damage, and apoptosis in rats. Toxicology industrial health 31(12):1106-1115

53. Ansari MA, Abdul HM, Joshi G, Opii WO, Butterfield DA (2009) Protective effect of quercetin in primary neurons against $A \beta(1-42)$ : relevance to Alzheimer's disease. The Journal of nutritional biochemistry. Apr 1;20(4):269 - 75

54. Prado VF, Martins-Silva C, de Castro BM, Lima RF, Barros DM, Amaral E, Ramsey AJ, Sotnikova TD, Ramirez MR, Kim HG, Rossato Jl. Mice deficient for the vesicular acetylcholine transporter are myasthenic and have deficits in object and social recognition. Neuron. 2006 Sep 7;51(5):601-12

55. Dai J, Buijs RM, Kamphorst W, Swaab DF (2002 Sep) Impaired axonal transport of cortical neurons in Alzheimer's disease is associated with neuropathological changes. Brain research 6(1-2):138-144 948(

56. Fasolo JM, Vizuete AF, Rico EP, Rambo RB, Toson NS, Santos E, de Oliveira DL, Gonçalves CA, Schapoval EE, Heriques AT (2021) Anti-inflammatory effect of rosmarinic acid isolated from Blechnum brasiliense in adult zebrafish brain. Comparative Biochemistry and Physiology Part C: Toxicology \& Pharmacology. Jan 1;239:108874

\section{Figures}




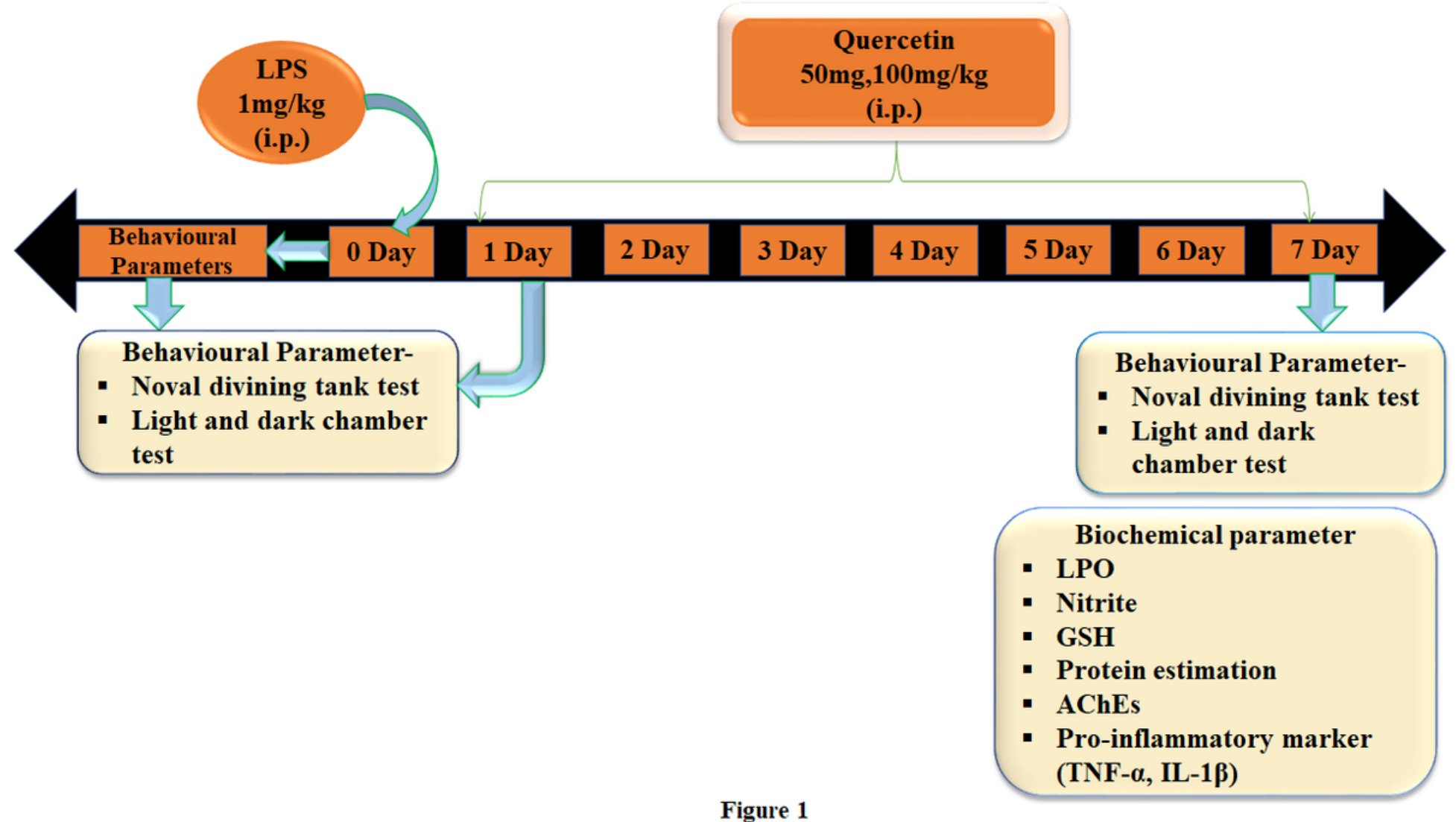

Figure 1

Experimental protocol.

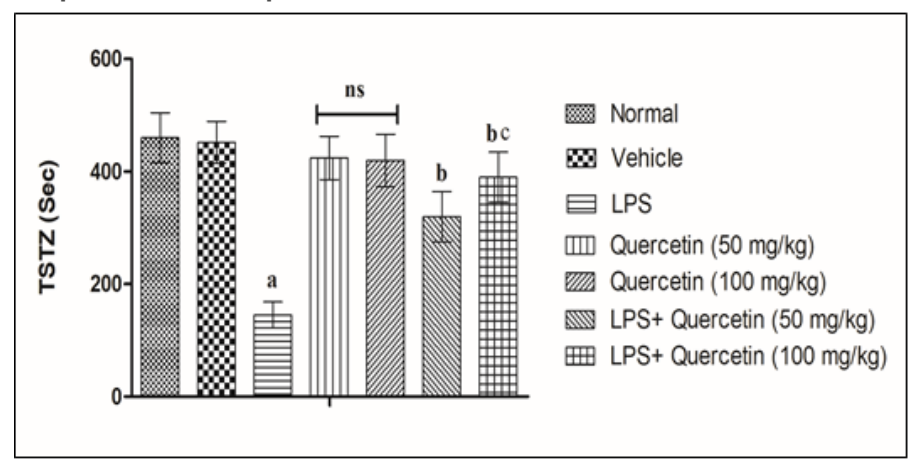

Figure 2A

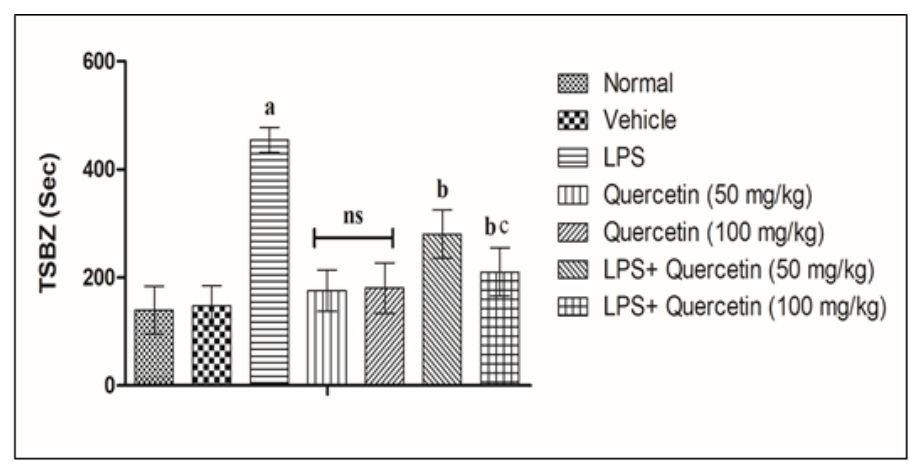

Figure 2B

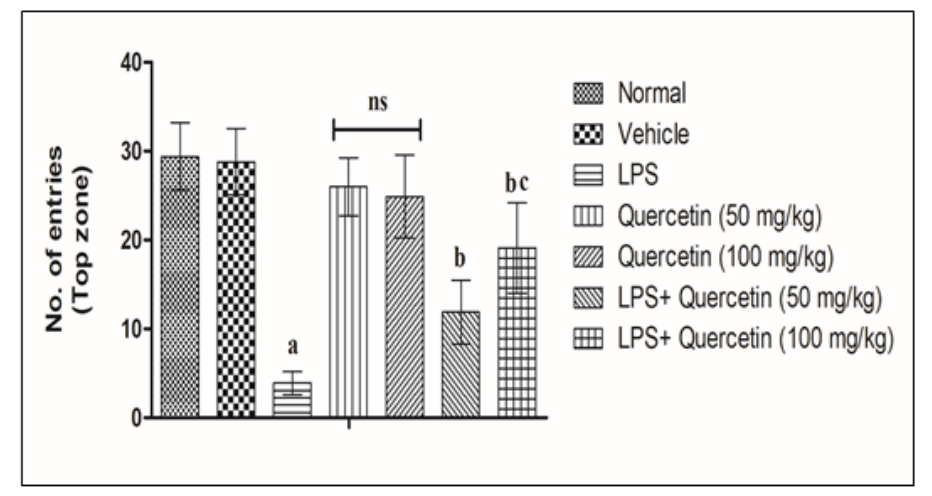

Figure 2C 
Figure 2

Effect of Quercetin treatment on novel diving tank in LPS treated zebrafish. (A) TSTZ (B) TSBZ (C) Number of entries in top zone. Zebrafish were post treated with different doses of quercetin ( $50 \& 100$ $\mathrm{mg} / \mathrm{kg}$ ) for 7 days. Data are expressed as the mean \pm SD. ap $<0.001$ vs Normal, $b p<0.001$ vs LPS, $c p<0.01$ vs LPS+ Quercetin $(50 \mathrm{mg} / \mathrm{kg})$, nsp $>0.05$ vs normal group. Statistical analysis performed by one-way ANOVA followed by post test Tukey multiple comparison. [LPS: lipopolysaccharide; TSTZ: time spend in top zone; TSBZ: time spend in bottom zone].

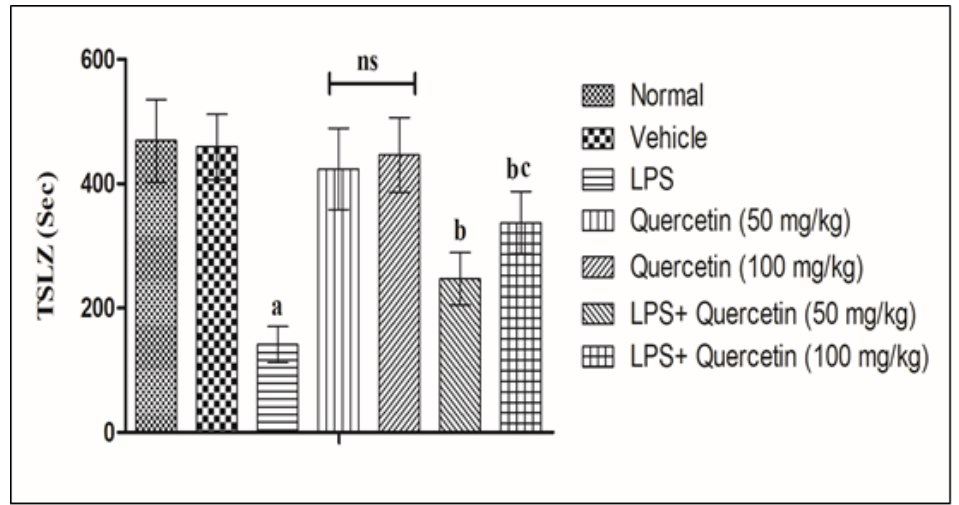

Figure 3A

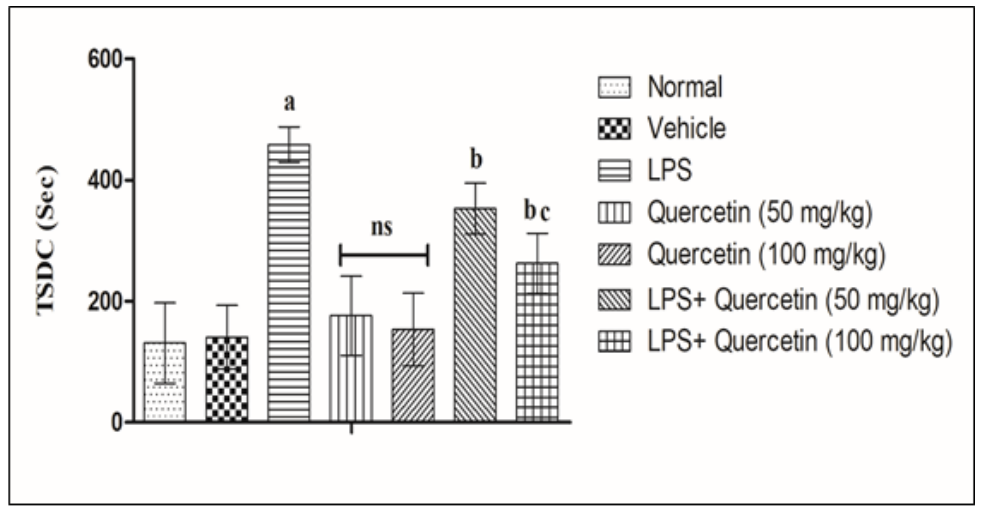

Figure 3B

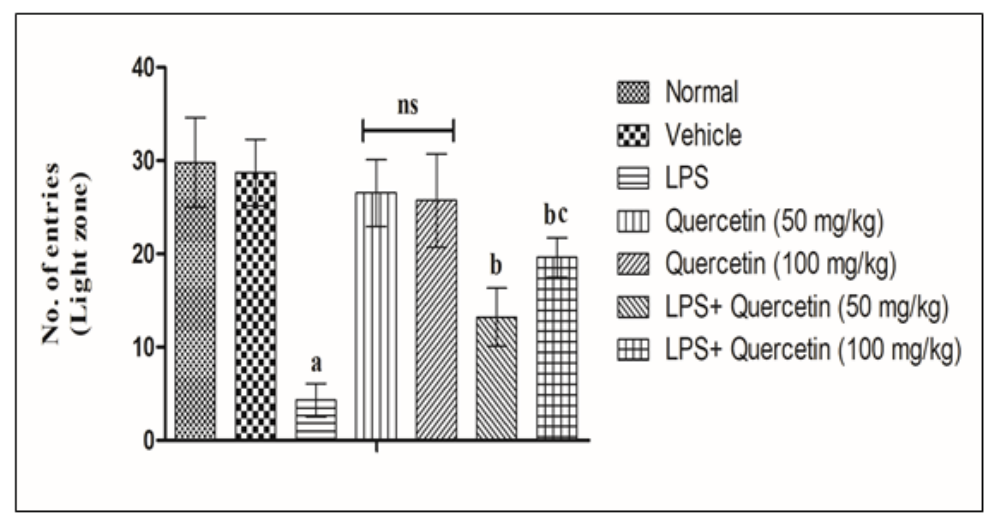

Figure 3C

\section{Figure 3}

Effect of quercetin treatment on light-dark chamber test in LPS treated zebrafish. (A) TSLZ (B) TSDC (C) Number of entries in light zone. Zebrafish were post treated with different doses of quercetin $(50 \& 100$ $\mathrm{mg} / \mathrm{kg}$ ) for 7 days. Data are expressed as the mean \pm SD. ap $<0.001$ vs Normal, $b p<0.001 \mathrm{vs} \mathrm{LPS,} c p<0.01$ vs LPS+ Quercetin $(50 \mathrm{mg} / \mathrm{kg}$ ) nsp $>0.05$ vs normal group. Statistical analysis performed by one-way ANOVA followed by post test Tukey multiple comparison. [LPS: lipopolysaccharide; TSLZ: time spend in light zone; TSDC: time spend in dark compartment]. 


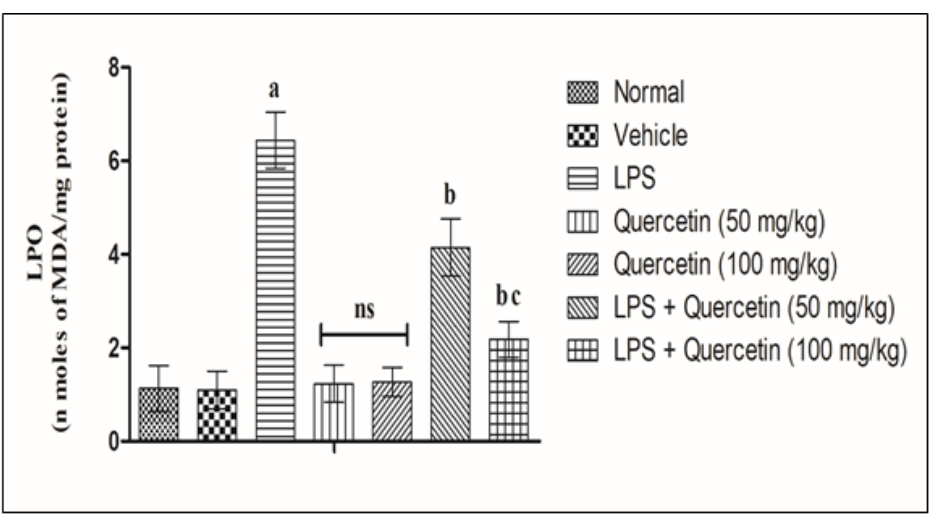

Figure 4A

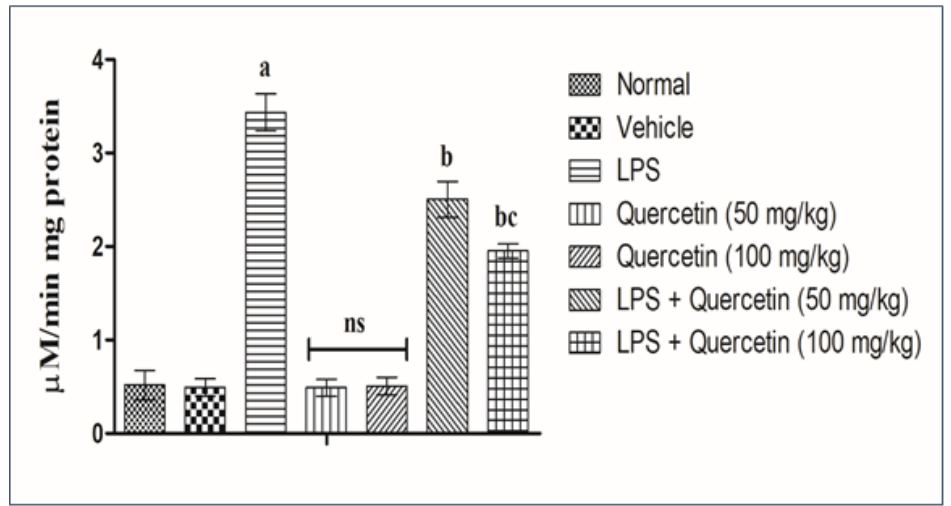

Figure 4C

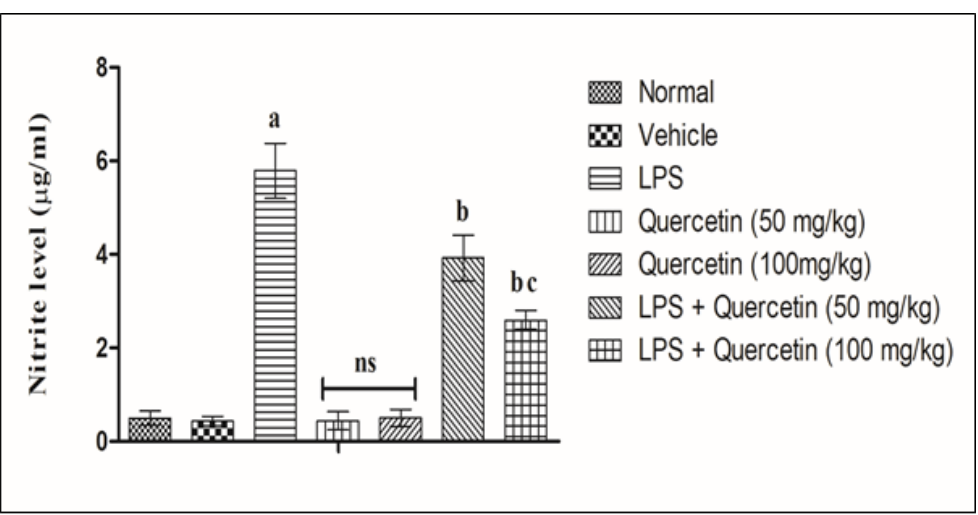

Figure 4B

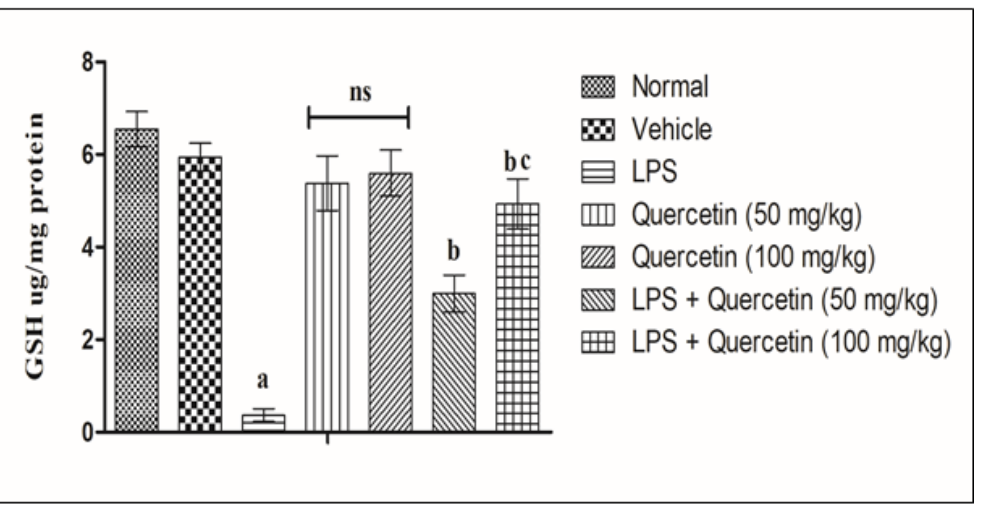

Figure 4D

\section{Figure 4}

Assessment of oxidative stress markers. (A) LPO (B) nitrite (C) AChEs and (D) GSH. Zebrafish were post treated with different doses of quercetin $(50 \& 100 \mathrm{mg} / \mathrm{kg})$ for 7 days. Data are expressed as the mean \pm SD. ap $<0.001$ vs Normal, bp $<0.001$ vs LPS, $c p<0.01$ vs LPS+ Quercetin $(50 \mathrm{mg} / \mathrm{kg}) \mathrm{nsp}>0.05$ vs normal group. Statistical analysis performed by one-way ANOVA followed by post test Tukey multiple comparison. [LPS: lipopolysaccharide; LPO: lipid peroxidation; AChEs: Acetylcholinesterase; GSH: glutathione].

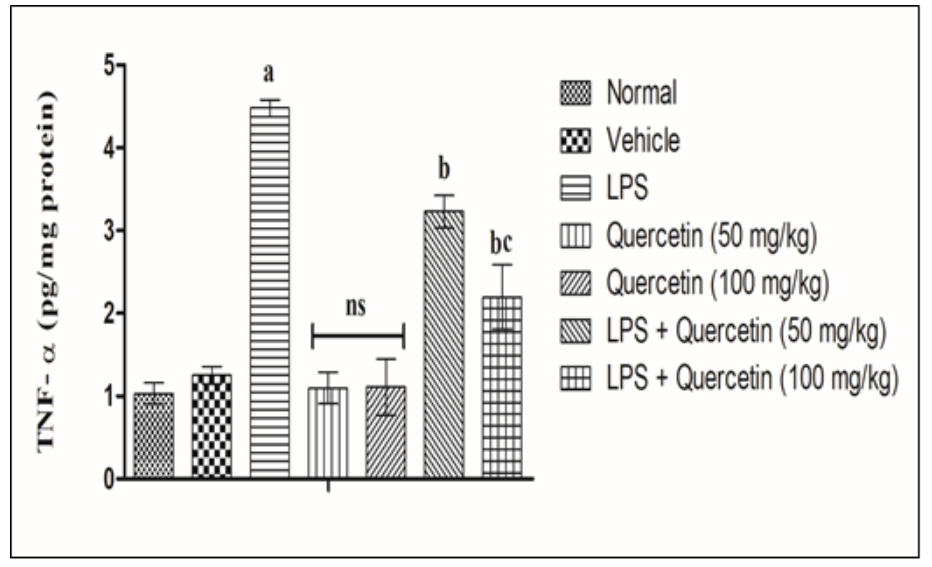

Figure 5A

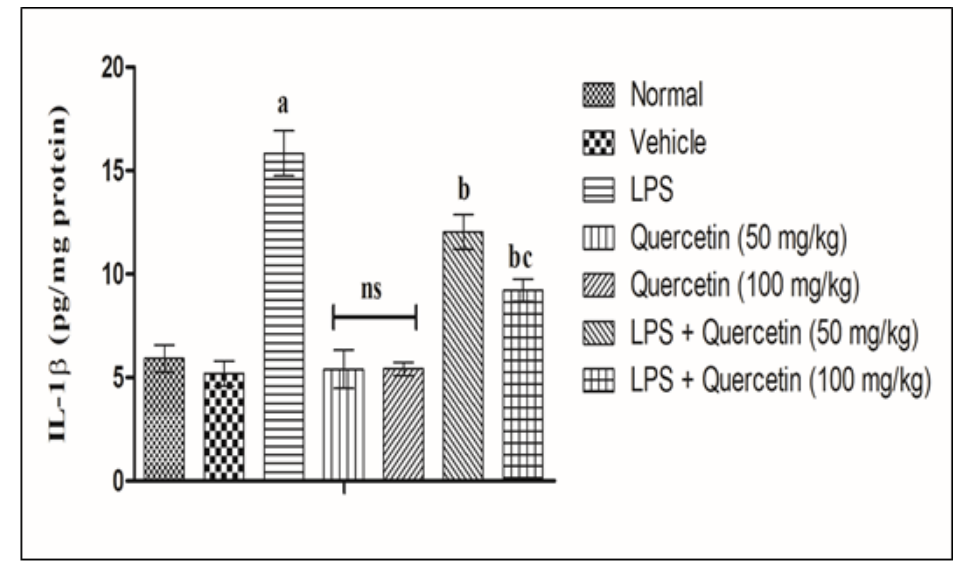

Figure 5B

Figure 5 
Effect of quercetin treatment on TNF-a, IL-1 $\beta$ level in LPS treated zebrafish. (A) TNF-a (B) IL-1 $\beta$. Zebrafish were post treated with different doses of quercetin $(50 \& 100 \mathrm{mg} / \mathrm{kg}$ ) for 7 days. Data are expressed as the mean \pm SD. ap $<0.001$ vs Normal, bp $<0.001$ vs LPS, $c p<0.01$ vs LPS+ Quercetin $(50 \mathrm{mg} / \mathrm{kg}), \mathrm{nsp}>0.05$ vs normal group. Statistical analysis performed by one-way ANOVA followed by post test Tukey multiple

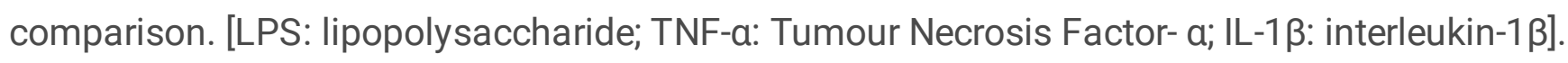

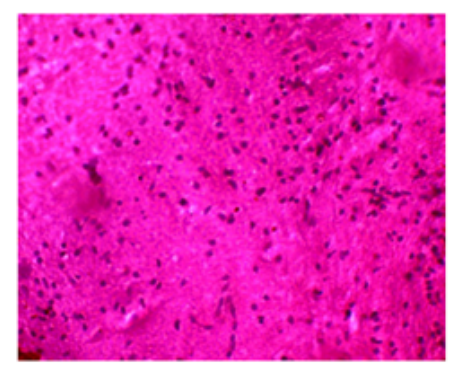

Normal

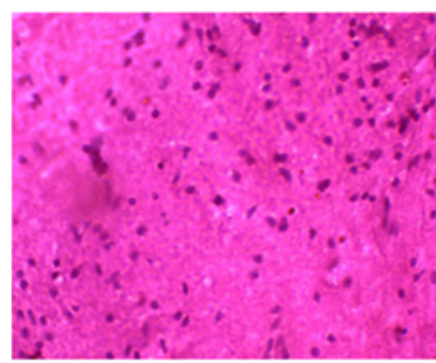

Vehicle

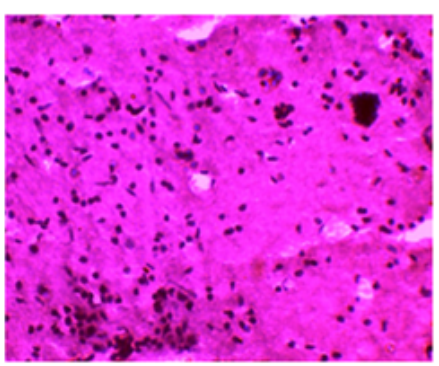

Quercetin (50mg/kg)

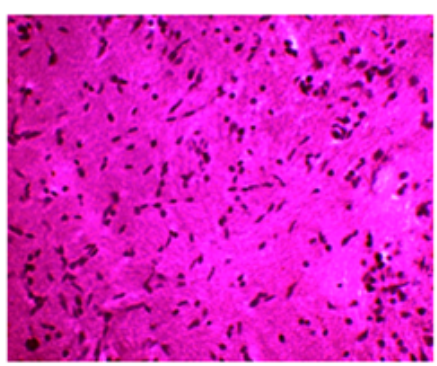

Quercetin (100mg/kg)

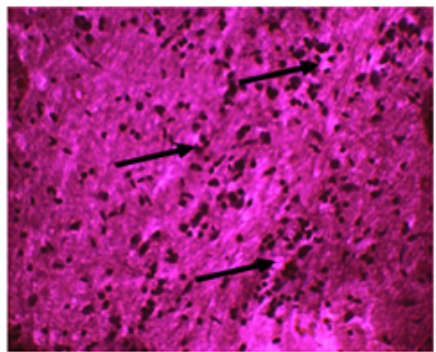

LPS

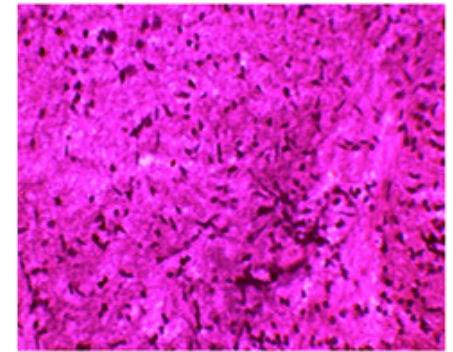

LPS+ Quercetin (50mg/kg)

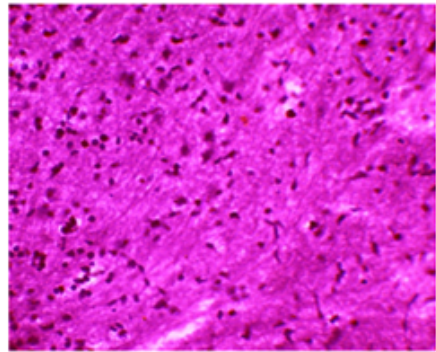

LPS+ Quercetin (100mg/kg)

Figure 6

\section{Figure 6}

Effect of quercetin treatment on histopathological damagesin LPS treated zebrafish. Photomicrograph brain of normal, vehicle and quercetin (50 and $100 \mathrm{mg} / \mathrm{kg}$ ) zebrafish showing normal neuronal cells, LPS treated group showed disarrangement of various cell layers and pyramidal neuronal cell loss (straight arrow) as compared to normal group. However, quercetin (50 and $100 \mathrm{mg} / \mathrm{kg}$ ) treatment altered the effects as seen against LPS group. 


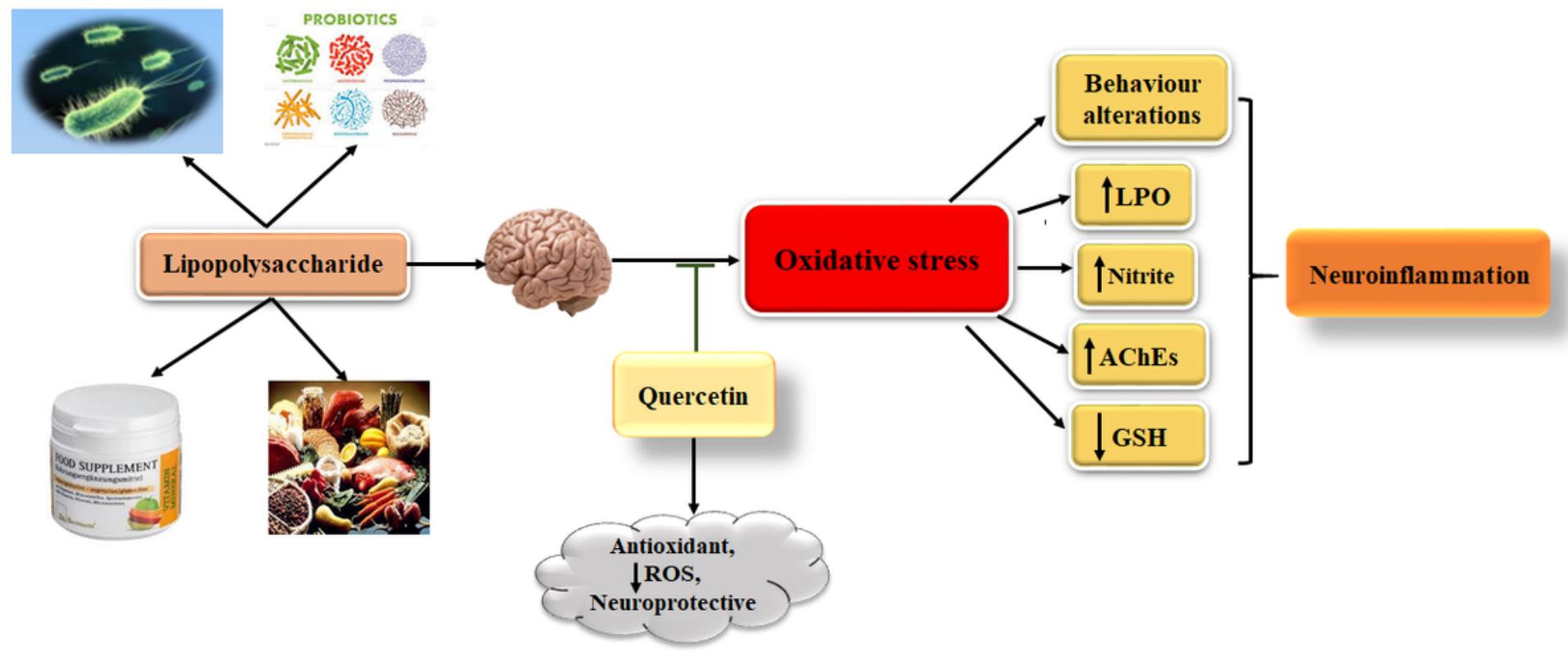

Figure 7

Figure 7

Mechanism of quercetin in reducing neuroinflammation. 